\title{
Antibacterial and antioxidant activity of leaf organic extracts of local cultivars of Murraya koenigii (L.) Spreng from Tamilnadu
}

\section{Kavitha}

School of Biosciences and Technology, VIT University, Vellore-632014, Tamilnadu, India

\begin{abstract}
The aim of the present study was to evaluate the antibacterial activity against five bacterial pathogens and antioxidant activity of three organic extracts prepared from the leaves of local cultivars of Murraya koenigii. Agar well diffusion was utilized to determine the zone of inhibition. Broth microdilution was employed to find out the minimal inhibitory concentration (MIC) and minimal bactericidal concentration (MBC). Anti-oxidant activity was analysed using 2,2-Diphenyl-1-picryl hydrazyl (DPPH) free radical scavenging assay. The organic extracts displayed promising antibacterial activity against Staphylococcus aureus, Escherichia coli and Pseudomonas aeruginosa. Ethyl alcohol extract presented highest inhibitory activity when compared to hexane and chloroform extracts. In relation to agar diffusion method, the ethyl alcohol extract displayed lowest MIC and MBC value of 12.5 and $25 \mathrm{mg} \mathrm{ml}^{-1}$ against Staphylococcus aureus and same MIC and MBC value of 25 and $50 \mathrm{mg} \mathrm{ml}^{-1}$ against Escherichia coli and Pseudomonas aeruginosa. The radical-scavenging activity of ethyl alcohol extract $\left(\mathrm{IC}_{50}=30 \mu \mathrm{g} \mathrm{ml}^{-1}\right.$ ) is very close to that of the standard compound, gallic acid ( $\mathrm{IC}_{50}$ value of $35 \mathrm{\mu g} \mathrm{ml}^{-1}$ ). The results suggested that the local cultivars of M. koenigii carry beneficial health effects in terms of antimicrobial and anti-oxidant activities and could be used as a promising dietary supplement.
\end{abstract}

KEY WORDS: MURRAYA KOENIGII; ETHYL ALCOHOL EXTRACT; CARBAZOLE ALKALOID; ANTIBACTERIAL ACTIVITY; ANTIOXIDANT ACTIVITY

ARTICLE INFORMATION:

*Corresponding Author: mkavitha1972@gmail.com

Received $27^{\text {th }}$ Nov, 2017

Accepted after revision $26^{\text {th }}$ Sep, 2017

BBRC Print ISSN: 0974-6455

Online ISSN: 2321-4007 CODEN: USA BBRCBA

Thomson Reuters ISI ESC and Crossref Indexed Journal

* NAAS Journal Score 2017: 4.31 Cosmos IF: 4.006

- A Society of Science and Nature Publication, 2017. All rights reserved.

Online Contents Available at: http//www.bbrc.in/

DOI: $10.21786 / \mathrm{bbrc} / 10.3 / 4$ 


\section{INTRODUCTION}

Spices and herbs which are used in food preparations traditionally are well known to contain several health promoting bioactive substances. Herbal medicines are used alternatively in many countries to cure many ailments (Kamboj, 2000). Herb based medicines are now marketed as nutraceuticals (health foods) (Brower, 1998). Indian Ayurvedic medicine is believed to be more than 5000 years old and it was well practiced and well recorded over the years (Garodia et al., 2007). Herbal drugs are generally used to prevent and treat various diseases and ailments or to support health and healing (De Smet, 1997). The World Health Organization (WHO) has also recognized the importance of traditional medicine and has set precise guidelines for the evaluation of the safety, efficacy, and quality of herbal medicines. In recent years the research on the medicinal properties of various traditionally used medicinal plants has gained considerable interest in order to ascertain their true medicinal values and also to assess their toxicity (Newman and Crag, 2007). Some drugs have been discontinued due to their toxicity, while others have been modified or combined with additional herbs to counterbalance side effects (Harish, 2001).

Bioactive principles of plants, also known as secondary metabolites exert a range of pharmacological activities in human beings besides serving as defense barriers in plants (Paul et al., 2015). They are responsible for therapeutic activities like hypoglycemic, anti-diabetic, anti-oxidant, anti-microbial, anti-inflammatory, anti-carcinogenic, anti-malarial, anti-cholinergic, anti-leprosy activities etc. (Makri and Kintzios, 2007; Negi et al., 2011). Common bioactive principles present in plants are, alkaloids, flavonoids, polyphenols, terpenoids, coumarins, tannins, saponins, anthocyanins and glycosides (Paul et al., 2015).

Additionally secondary metabolites also prevent spoilage and deterioration of food products Panghal et al., 2011). Murraya koenigii (L.) Spreng popularly known as curry leaf plant is a familiar spice used in India for its characteristic flavour and aroma. According to Wealth of India, it is also used in traditional Indian medicine as analgesic, febrifuge, stomachic, carminative and for the treatment of dysentery and skin eruptions. Recent studies on $M$. koenigii revealed its medicinal values like antidiarrhoeal, antimicrobial, hepatoprotective, radical-scavenging, hypoglycemic, and immunomodulatory properties (Maa et al., 2016). Phytochemical analysis of leaves, bark and root showed the presence of several bioactive constituents like carbazole alkaloids, $\beta$-carotene, polyphenols, terpenoids and coumarins (Malwal and Sarin, 2011; Gahlawat et al., 2014).

The pharmacological activities of $M$. koenigii as reported in different studies seem to exhibit a certain variation which is attributed mainly to the climatic differences among locations (Onayade and Adebajo, 2000). Therefore it has become a common practice to confirm that the local cultivars of M. koenigii possess the expected beneficial effects when consumed regularly. There are a few reports on phytochemical analysis and pharmacological activities of $M$. koenigii from India (Ningappa et al., 2008; Panghal et al., 2011; Malwal and Sarin, 2011; Biswas et al., 2012). But to my best knowledge, in recent years there are no studies on the antioxidant and antimicrobial activities of M. koenigii from Tamilnadu, a southern state of India. Therefore the present study on antibacterial and antioxidant activity of leaf organic extracts of local cultivars of Murraya koenigii from Tamilnadu was undertaken.

\section{MATERIALS AND METHODS}

2,2-Diphenyl-1-picrylhydrazyl (DPPH) was procured from Sigma chemicals. Mueller Hinton agar and broth were purchased from Hi-Media, Mumbai. All other chemicals used were of analytical grade commercially available in India.The antibacterial activity of the organic extracts was tested against five bacterial strains. The only Gram positive bacterium included in the study was Staphylococcus aureus MTCC 96 (ATCC 9144). Four Gram negative bacteria used were Escherichia coli MTCC 901 (ATCC 13534), Klebsiella pneumoniae MTCC 109 (ATCC 15380), Salmonella paratyphi MTCC 735 and Pseudomonas aeruginosa MTCC 8291. All these bacteria were obtained from Microbial Type Culture Collection (MTTC), Institute of Microbial Technology, Chandigarh, India and they were maintained on nutrient agar. $M$. koenigii leaves were collected locally from various locations of Tamil Nadu, India and authenticated by Botanist. Fresh leaves were washed thoroughly and dried under shade till constant weight. The dried leaves were ground to powder in a mixer grinder.

$100 \mathrm{~g}$ of shade dried M. koenigii leaves powder was extracted with hexane, chloroform and ethanol separately at room temperature for 2 days and then the solvents were evaporated using vacuum rotary evaporator at $50^{\circ} \mathrm{C}$. The organic extracts thus obtained were dried at room temperature till constant weight and then stored in brown bottles at $4^{\circ} \mathrm{C}$ for further study.

Antibacterial activity of the three organic extracts obtained from $M$. koenigii was evaluated by agar well diffusion method on Mueller-Hinton agar (MHA). The bacterial strains were grown on MHA and suspensions were prepared to match $0.5 \mathrm{McF}$ arland standard. $100 \mu \mathrm{l}$ of the suspension was spread on MHA plates. Wells of $6 \mathrm{~mm}$ diameter were punched in the seeded agar using sterile borer. Test well were loaded with $50 \mu$ l extracts 
(100 mg ml-1) and negative control well loaded with same volume of solvent. Ampicillin and streptomycin were used as a positive control. The plates were incubated at $37^{\circ} \mathrm{C}$ for $24 \mathrm{~h}$. The diameter of inhibition zones were measured in mm and results were recorded.

Minhibitory concentration (MIC) of the organic extracts was tested by the standard Clinical and laboratory standards institute (CLSI) methods (Wayne, 2008). MIC was the lowest concentration of the extract which gives no visible bacterial growth. Broth microdilution technique was used to determine the MIC (Elansary et al., 2012). The organic extracts from M. koenigii were serially diluted to obtain the dilutions, 200, 100, 50, 25, $12.5,6.25$ and $3.12 \mathrm{mg} \mathrm{ml}^{-1}$. $100 \mu \mathrm{l}$ from each dilution was transferred to respective wells followed by $90 \mu \mathrm{l}$ of double strength Mueller-Hinton broth (MHB). Finally 10 $\mu \mathrm{l}$ respective bacterial suspensions were added to give final dilution of $100,50,25,12.5,6.25,3.12$ and 1.56 $\mathrm{mg} \mathrm{ml} \mathrm{m}^{-1}$ and the microtiter plate was incubated at $37^{\circ} \mathrm{C}$ for $24 \mathrm{~h}$. Blank, positive and negative controls were in place. After incubation, the lowest concentrations of the extract, which did not show any visual growth of test organisms, were considered as MICs.

Minimum bactericidal concentration (MBC) of the organic extracts was also determined by the standard CLSI methods (Wayne, 2008). MBC was the lowest concentration of the extract which kills the initial bacterial inoculum. Broth microdilution technique was performed to determine the MBC. The extracts from M. koenigii were serially diluted to obtain the dilutions, 200, 100, 50, $25,12.5,6.25$ and $3.12 \mathrm{mg} \mathrm{ml}^{-1} .100 \mu \mathrm{l}$ from each dilution was added to corresponding wells followed by $90 \mu \mathrm{l}$ of double strength MHB. At last $10 \mu \mathrm{l}$ respective bacterial suspensions were transferred to provide final dilution of 100, 50, 25, 12.5, 6.25, 3.12 and $1.56 \mathrm{mg} \mathrm{ml}^{-1}$ and the plate was incubated at $37^{\circ} \mathrm{C}$ for $24 \mathrm{~h}$. Blank, positive and negative controls were also included. After incubation, the wells which did not show any visual growth of test organisms were considered. $100 \mu \mathrm{l}$ of the sample from those wells were transferred aseptically onto MHA, spread uniformly and the plates were incubated at $37^{\circ} \mathrm{C}$ for $24 \mathrm{~h}$. After incubation, the concentrations at which no visible growth was seen were fixed as the MBC.

Free radical scavenging activity of the organic extracts from $M$. koenigii was evaluated by its ability to scavenge DPPH (Elansary et al., 2012). DPPH is a free radical, but stable in nature. The DPPH solution is initially violet in color which fades when antioxidants donate hydrogen. The change in color is monitored using a spectrophotometer and thus the DPPH free radical scavenging activity is calculated (Molyneux, 2004). A stock solution of 0.1 $\mathrm{mM}$ DPPH in ethanol was prepared. Test concentrations of organic extracts were made in the range of 50-250 $\mu \mathrm{g}$ $\mathrm{ml}^{-1}$ in ethanol. Gallic acid was used as standard. $1 \mathrm{ml}$ of DPPH stock and $3 \mathrm{ml}$ of test samples were mixed and allowed to react at room temperature for $30 \mathrm{~min}$. The absorbance was measured at $517 \mathrm{~nm}$ using an ultraviolet visible spectrophotometer (Shimadzu, Japan). Lower absorbance of the reaction mixture indicated the higher free radical scavenging activity (Saikia and Upadhyaya, 2011). The percentage of free radical scavenging was calculated using the following Eq.

$$
\text { DPPH scavenging activity }(\%)=\frac{(A 0-A T)}{A 0} \times 100
$$

where A0 is the absorbance of the DPPH solution and AT is the absorbance of the test or reference. The percentage of free radical scavenging was then plotted against the concentration and a regression equation was obtained to calculate the $\mathrm{IC}_{50}$ which is defined as the total antioxidants necessary to decrease the initial DPPH radical by 50\% (Koleva et al., 2002).

All the experiments were done in triplicates. The values in the tables represent the arithmetic mean and standard deviation or mean. The standard error was within experimental limits.

\section{RESULTS AND DISCUSSION}

The organic extracts obtained from M. koenigii were less viscous in nature and brownish in colour. The yield of the extracts was estimated to be 7, 6.5 and $9.2 \%(\mathrm{v} / \mathrm{w})$ for hexane, chloroform and ethanol respectively. The yield in the present study was comparable to the yield reported in other investigations (Ningappa et al., 2008; Brind et al., 2014).

The results of antibacterial activity were presented in Table 1. Based on the diameter of zone of inhibition, the three organic extracts exhibited inhibitory activity against Staphylococcus aureus, Escherichia coli and Pseudomonas aeruginosa (Figure 1). Klebsiella pneumoniae and Salmonella paratyphi were found to be resistant except for chloroform extract which showed a very faint zone of inhibition. The organic extracts presented a good potential of antibacterial activity against Escherichia coli and Pseudomonas aeruginosa with the zones of inhibition well above standard antibiotic. Ethyl alcohol extract displayed highest inhibitory activity when compared to hexane and chloroform extracts. The results were comparable to that of previous studies in which the researchers reported that the various organic extracts of M. koenigii exhibited significant antimicrobial activity against both Gram positive and Gram negative bacteria (Panghal et al., 2011; Baskaran et al., 2011). This property is attributed to several carbazole alkaloids present in the organic extracts (Malwal and Sarin, 2011). 


\begin{tabular}{|c|c|c|c|c|}
\hline \multirow[t]{2}{*}{ Test organism } & \multicolumn{4}{|c|}{ Zone of Inhibition (in $\mathrm{mm}$ ) } \\
\hline & Hexane & Chloroform & Ethyl alcohol & Standard \\
\hline Staphylococcus aureus & $15.5 \pm 0.5$ & $16.23 \pm 0.87$ & $16.33 \pm 0.57$ & $23.16 \pm 0.76$ \\
\hline Escherichia coli & $11.5 \pm 0.86$ & $12.83 \pm 0.28$ & $15.83 \pm 0.28$ & $11.83 \pm 0.76$ \\
\hline Klebsiella pneumoniae & 0 & $7.83 \pm 0.76$ & 0 & $11.86 \pm 0.8$ \\
\hline Salmonella paratyphi & 0 & $7.5 \pm 0.5$ & 0 & $14.83 \pm 076$ \\
\hline Pseudomonas aeruginosa & $13.66 \pm 0.76$ & $13.66 \pm 0.76$ & $14.83 \pm 0.76$ & $12.9 \pm 0.85$ \\
\hline
\end{tabular}

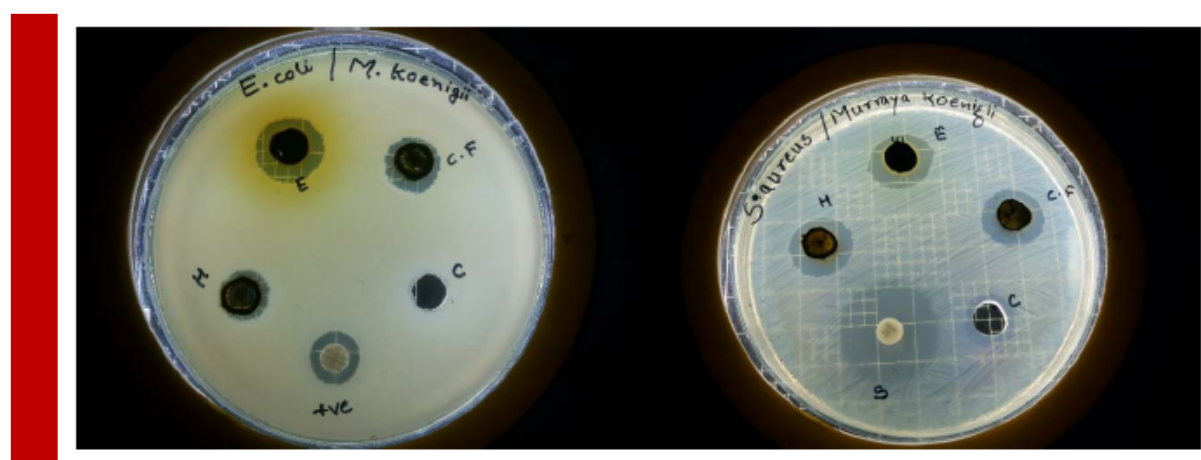

A

B

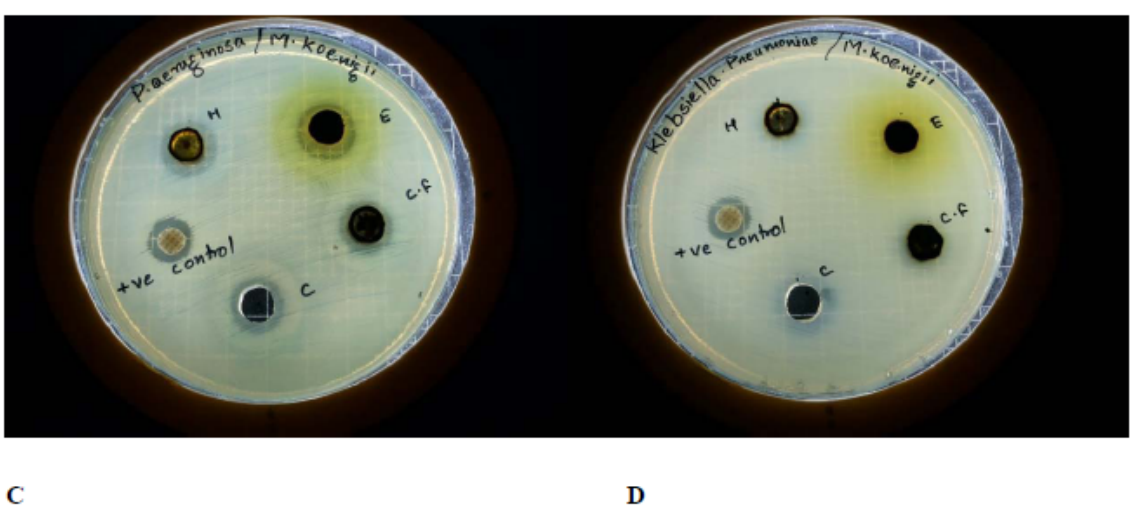

FIGURE 1. MHA plates exhibiting zone of inhibition of $M$. koenigiiorganic extracts against (A) Escherichia coli, (B) Staphylococcus aureus, (C) Pseudomonas aeruginosa and (D) Klebsiella pneumoniae.

The results of MIC and MBC of ethyl alcohol extract were summarized in Table 2. Relative to the results of agar diffusion method, the extract displayed lowest MIC and MBC value of 12.5 and $25 \mathrm{mg} \mathrm{ml}^{-1}$ respectively against Staphylococcus aureus. The extract produced same MIC and MBC value of 25 and $50 \mathrm{mg} \mathrm{ml}^{-1}$ against Escherichia coli and Pseudomonas aeruginosa. The results are equitable to the results presented by Panghal et al. in which the organic extracts prepared from the leaves of $M$. koenigii manifested slightly better MIC values against the clinical isolates (Panghal et al., 2011). Zinc oxide

\begin{tabular}{|c|c|c|c|c|}
\hline \multirow{2}{*}{ Test organism } & \multicolumn{2}{|c|}{ MIC $\left(\mathrm{mg} \mathrm{ml}^{-1}\right)$} & \multicolumn{2}{|c|}{$\mathrm{MBC}\left(\mathrm{mg} \mathrm{ml}^{-1}\right)$} \\
\hline & Test & Standard & Test & Standard \\
\hline $\begin{array}{l}\text { Staphylococcus } \\
\text { aureus }\end{array}$ & 12.5 & 3.12 & 25 & 6.25 \\
\hline Escherichia coli & 25 & 25 & 50 & 50 \\
\hline $\begin{array}{l}\text { Pseudomonas } \\
\text { aeruginosa }\end{array}$ & 25 & 25 & 50 & 50 \\
\hline
\end{tabular}

Table 2. Minimum Inhibitory Concentration and Minimum Bactericidal Concentration of $M$. koenigi organic extracts 


\begin{tabular}{|c|c|c|c|c|c|}
\hline $\begin{array}{l}\text { Concentration } \\
(\mu \mathrm{g} \text { ml-1) }\end{array}$ & \multicolumn{4}{|c|}{ DPPH scavenging activity (\%) } & IC50 value ( $\mu \mathrm{g} \mathrm{ml-1)}$ \\
\hline & Ethyl alcohol & Hexane & Chloroform & Gallic acid & \multirow{6}{*}{$\begin{array}{l}\text { Gallic acid }=35 \\
\text { Ethyl alcohol }=30 \\
\text { Hexane }=22 \\
\text { Chloroform }=27\end{array}$} \\
\hline 20 & 12 & 9 & 9 & 13 & \\
\hline 40 & 23 & 16 & 21 & 28 & \\
\hline 60 & 35 & 25 & 33 & 42 & \\
\hline 80 & 48 & 34 & 42 & 55 & \\
\hline 100 & 62 & 45 & 54 & 68 & \\
\hline
\end{tabular}

nanoparticles synthesized using the leaf extract of $M$. koenigii displayed almost similar results to the present study (Elumalai et al., 2015). Antioxidant protein isolated from the leaves of M. koenigii also exhibited comparable results (Ningappa et al., 2010). The variation in the antimicrobial activity of $M$. koenigii organic extracts specified in various studies may be due to the differences in chemical composition which can result from the climatic differences among locations (Paul, 2015). Though several compounds like tocopherol, $\beta$-carotene, lutein and alkaloids (Khanum et al., 2000) are reported in the leaf organic extracts, carbazole alkaloids are accounted for the antimicrobial activity (Ramsewak et al., 1999).

The results of free radical-scavenging ability of organic extracts of $M$. koenigii measured by the DPPH assay were given in Table 3. Ethyl alcohol extract displayed highest radical scavenging activity with the $\mathrm{IC}_{50}$ value of $30 \mu \mathrm{g} \mathrm{ml}^{-1}$ than the rest two extracts. The radical-scavenging activity of ethyl alcohol extract is very close to that of the standard, gallic acid exhibiting the $\mathrm{IC}_{50}$ value of $35 \mu \mathrm{g} \mathrm{ml} \mathrm{m}^{-1}$. This is in agreement with other studies on anti-oxidant activity of leaf extracts of M. koenigii (Rao et al., 2007; Ningappa et al., 2008; Kusuma et al., 2011). The antioxidant activity of organic extracts from M. koenigii is attributed to the presence of polyphenolic compounds and carbazole alkaloids (Rao et al., 2007; Garodia et al., 2007). Ethyl alcohol extract exhibited greater radical-scavenging activity than the other two extracts and this can be inferred as ethanol is effective in extracting polyphenols (Singh et al., 2011).

\section{CONCLUSION}

As substantiated in the study, the ethyl alcohol extract from the leaves of $M$. koenigii, grown locally to fulfil culinary needs of Indian cuisine displayed excellent antimicrobial activity against both Gram positive and negative bacteria and also exhibited a quality free radical scavenging activity. Climate of the location and growing season greatly influence the chemical composition of M. koenigii and thus have an impact on the biological activities. The above study confirmed that the local cultivars of $M$. koenigii possess beneficial health effects in terms of antimicrobial and anti-oxidant activities. Consequently, local cultivars of M. koenigii could be effectively used as spice and dietary supplement, however further study on molecular mechanism behind the role of various constituents on radical scavenging and antimicrobial inhibition needs to be done.

\section{REFERENCES}

Baskaran, C., Rathabai, V. and Kanimozhi, D. (2011) Screening for antimicrobial activity and phytochemical analysis of various leaf extract of Murraya koenigii. International Journal of Research in Ayurveda and Pharmacy, 2, 1807-1810.

Biswas, A.K., Chatli, M.K. and Sahoo, J. (2012) Antioxidant potential of curry (Murraya koenigii L.) and mint (Mentha spicata) leaf extracts and their effect on colour and oxidative stability of raw ground pork meat during refrigeration storage. Food Chemistry, 133, 467-472.

Brind, L., Misra, A. and Srivastava, S. (2014) Evaluation of central nervous system stimulating and analgesic activities of Murraya koenigii leaves. Journal of Acute Medicine, 4, 81-85.

Brower, V. (1998) Nutraceuticals: Poised for a healthy slice of the healthcare market? Nature Biotechnology, 16, 728-731.

De Smet, P.A. (1997) The role of plant derived drugs and herbal medicines in healthcare drugs. Drugs, 54, 801-840.

Elansary, H.O., Salem, M.Z.M., Ashmawy, N.A. and Yacout, M.M. (2012) Chemical composition, antibacterial and antioxidant activities of leaves essential oils from Syzygium cumini L., Cupressus sempervirens L. and Lantana camara L. Egyptian Journal of Agricultural sciences, 4, 144-152.

Elumalai, K., Velmurugan, S., Ravi, S., Kathiravan, V. and Ashokkumar, S. (2015) Bio-fabrication of zinc oxide nanoparticles using leaf extract of curry leaf (Murraya koenigii) and its antimicrobial activities. Materials Science in Semiconductor Processing, 34, 365-372.

Gahlawat, D.K., Jakhar, S. and Dahiya, P. (2014) Murraya koenigii (L.) Spreng: an ethnobotanical, phytochemical and 
pharmacological review. Journal of Pharmacognosy and Phytochemistry, 3, 109-119.

Garodia, P., Ichikawa, H., Malani, N., Sethi, G. and Aggarwal, B.B. (2007) From ancient medicine to modern medicine: ayurvedic concepts of health and their role in inflammation and cancer. Journal of the Society for Integrative Oncology, 5, 25-37.

Harish, P. (2001) Herbal drugs. Current Science India, 81, 15.

Kamboj, V.P. (2000) Herbal medicine. Current Science India, 78, 35-39.

Khanum, F., Anilakumar, K.R., Sudarshan Krishna, K.R., Viswanathan, K.R. and Santhanam, K. (2000). Anticarcinogenic effects of curry leaves in dimethylhydrazine-treated rats. Plant Foods for Human Nutrition, 55, 347-355.

Koleva, I.I., van Beek, T.A., Linssen, J.P., de Groot, A. and Evstatieva, L.N. (2002) Screening of plant extracts for antioxidant activity: a comparative study on three testing methods. Phytochemical Analysis, 13, 8-17.

Kusuma, I.W., Kuspradini, H., Arung, E.T., Aryani, F., Min, Y.H., Kim, J.S., Kim, Y.U. (2011). Biological activity and phytochemical analysis of three Indonesian medicinal plants, Murraya koenigii, Syzygium polyanthum and Zingiber purpurea. Journal of Acupuncture and Meridian studies, 4, 75-79.

Maa, Q.G., Xu, K., Sang, Z.P., Wei, R.R., Liu, W.M., Su, Y.L., Yang, J.B., Wang, A.G., Ji, T.F. and Li, L.J. (2016) Alkenes with anti-oxidative activities from Murraya koenigii (L.) Spreng. Bioorganic and Medicinal Chemistry Letters, 26, 799803.

Makri, O. and Kintzios, S. (2007) Ocimum sp. (basil): Botany, cultivation, pharmaceutical properties, and biotechnology. Journal of Herbs Spices and Medicinal Plants, 13, 123-150.

Malwal, M. and Sarin, R. (2011) Antimicrobial efficacy of Murraya koenigii (Linn.) Spreng. root extracts. Indian Journal of Natural Products and Resources, 2, 48-51.

Molyneux, P. (2004) The use of stable free radical diphenylpicryl-hydrazyl (DPPH) for estimating antioxidant activity. Songklanarin Journal of Science and technology, 26, 211-219.

Negi, J.S., Singh, P. and Rawat, B. (2011) Chemical constituents and biological importance of swertia: a review. Current Research in Chemistry, 3, 1-15.
Newman, D.J. and Crag, G.M. (2007) Natural products as sources of new drugs over the last 25 years. Journal of Natural Products, 70, 461-477.

Ningappa, M.B., Dhananjaya, B.L., Dinesha, R., Harsha, R. and Srinivas, L. (2010) Potent antibacterial property of APC protein from curry leaves (Murraya koenigii L.). Food Chemistry, 118, 747-750.

Ningappa, M.B., Dinesha, R. and Srinivas, L. (2008) Antioxidant and free radical scavenging activities of polyphenolenriched curry leaf (Murraya koenigii L.) extracts. Food Chemistry, 106, 720-728.

Onayade, O.A. and Adebajo, A.C. (2000) Composition of the oil of Murraya koenigii growing in Nigeria. Journal of Herbs Spices and Medicinal Plants, 7, 59-66.

Panghal, M., Kaushal, V. and Yadav, J.P. (2011) In vitro antimicrobial activity of ten medicinal plants against clinical isolates of oral cancer cases. Annals of Clinical Microbiology and Antimicrobials, 10, 21 .

Paul, C.C., Chiedozie, O.I. and Ferdinand, N.M. (2015) Bioactive principles from medicinal plants. Research Journal of Phytochemistry, 9, 88-115.

Ramsewak, R.S., Nair, M.G., Strasburg, G.M., De Witt, D.L. and Nitiss, J.L. (1999). Biologically active carbazole alkaloids from Murraya koenigii. Journal of Agricultural and Food Chemistry, 47, 444-447.

Rao, L.J.M., Ramalakshmi, K., Borse, B.B. and Raghavan, B. (2007). Antioxidant and radical-scavenging carbazole alkaloids from the oleoresin of curry leaf (Murraya koenigii Spreng). Food Chemistry, 100, 742-747.

Saikia, L.R. and Upadhyaya, S. (2011) Antioxidant activity, phenol and flavonoid content of some less known medicinal plants of Assam. International Journal of Pharma and Biosciences, 2, 383-388.

Singh, A.P., Wilson, T., Luthria, D., Freeman, M.R., Scott, R.M., Bilenker, D., Shah, S., Somasundaram, S. and Vorsa, N. (2011). LC-MS-MS characterization of curry leaf flavonols and antioxidant activity. Food Chemistry, 127, 80-85.

Wayne, P.A. (2008) Performance standards for antimicrobial susceptibility testing; eighteenth informational supplement, CLSI document M100-18, Clinical and Laboratory Standards Institute. 